\title{
Complication rates of CT-guided transthoracic lung biopsy: meta-analysis
}

\author{
W. J. Heerink ${ }^{1,2}$ • G. H. de Bock ${ }^{1,3}$ • G. J. de Jonge ${ }^{2}$ - H. J. M. Groen ${ }^{1,4}$. \\ R. Vliegenthart ${ }^{1,2}$ - M. Oudkerk ${ }^{1}$
}

Received: 21 October 2015 / Revised: 5 January 2016/Accepted: 5 April 2016 /Published online: 23 April 2016

(C) The Author(s) 2016. This article is published with open access at Springerlink.com

\begin{abstract}
Objectives To meta-analyze complication rate in computed tomography (CT)-guided transthoracic lung biopsy and associated risk factors.

Methods Four databases were searched from 1/2000 to $8 / 2015$ for studies reporting complications in CT-guided lung biopsy. Overall and major complication rates were pooled and compared between core biopsy and fine needle aspiration (FNA) using the random-effects model. Risk factors for complications in core biopsy and FNA were identified in metaregression analysis.

Results For core biopsy, 32 articles ( 8,133 procedures) were included and for FNA, 17 (4,620 procedures). Pooled overall complication rates for core biopsy and FNA were $38.8 \%$ (95\% CI: 34.3-43.5\%) and $24.0 \%$ (95\% CI: $18.2-$ $30.8 \%$ ), respectively. Major complication rates were $5.7 \%$ (95\% CI: 4.4-7.4\%) and $4.4 \%$ (95\% CI: 2.7-7.0\%), respectively. Overall complication rate was higher for core
\end{abstract}

Electronic supplementary material The online version of this article (doi:10.1007/s00330-016-4357-8) contains supplementary material, which is available to authorized users.

W. J. Heerink

w.j.heerink@umcg.nl

1 Center for Medical Imaging-North East Netherlands, University of Groningen, University Medical Center Groningen,

Groningen, Netherlands

2 Department of Radiology, University of Groningen, University Medical Center Groningen, Groningen, Netherlands

3 Department of Epidemiology, University of Groningen, University Medical Center Groningen, Groningen, Netherlands

4 Department of Pulmonary Medicine, University of Groningen, University Medical Center Groningen, Groningen, Netherlands biopsy compared to FNA $(p<0.001)$. For FNA, larger needle diameter was a risk factor for overall complications, and increased traversed lung parenchyma and smaller lesion size were risk factors for major complications. For core biopsy, no significant risk factors were identified.

Conclusions In CT-guided lung biopsy, minor complications were common and occurred more often in core biopsy than FNA. Major complication rate was low. For FNA, smaller nodule diameter, larger needle diameter and increased traversed lung parenchyma were risk factors for complications. Key Points

- Minor complications are common in CT-guided lung biopsy

- Major complication rate is low in CT-guided lung biopsy

- CT-guided lung biopsy complications occur more often in core biopsy than FNA

- Major complication rate is similar in core biopsy and FNA

- Risk factors for FNA are larger needle diameter, smaller lesion size

Keywords Lung neoplasms · Meta-analysis · Biopsy · Pneumothorax $\cdot$ Computed tomography, X-Ray

\begin{tabular}{|c|c|}
\hline \multicolumn{2}{|c|}{ Abbreviations } \\
\hline $95 \% \mathrm{CI}$ & $95 \%$ Confidence interval \\
\hline $\mathrm{CT}$ & Computed tomography \\
\hline FNA & Fine needle aspiration \\
\hline NOS & Newcastle Ottawa scale \\
\hline OR & Odds ratio \\
\hline SIR & Society of Interventional Radiology \\
\hline
\end{tabular}

\section{Introduction}

In the US, lung cancer screening by low-dose computed tomography (CT) is recommended for people at high risk [1], 
and the European Society of Radiology and the European Respiratory Society have recently recommended lung cancer screening within clinical trial setting or in routine clinical practice at certified medical centers [2]. This development will cause an increase in CT-detected lung nodules. Nodules $>10 \mathrm{~mm}$ and most likely even smaller nodules with high growth rate will be eligible for medical work-up, including CT-guided lung biopsy [2]. CT-guided transthoracic lung biopsy is a minimally invasive diagnostic procedure for tissue diagnosis of peripheral lung nodules. This can alternatively be achieved by surgery, but CT-guided transthoracic lung biopsy is less invasive and associated with lower costs.

CT-guided transthoracic lung biopsy is a widely accepted procedure [3, 4], although the reported complication rate varies greatly. Where some papers report a higher complication rate for core needle biopsy compared to fine needle aspiration (FNA) [5, 6], other studies [7, 8] do not. Yao et al. [9] concluded in a systematic review comparing FNA with core biopsy that no significant difference in complication rate between these techniques exists. They also concluded that core biopsy is generally reported to have a somewhat higher diagnostic performance compared to FNA, especially in identifying histological subtypes; the evidence is insufficient to support a difference.

Complication rate and diagnostic performance are the two main factors in choosing a diagnostic procedure. To determine the role of CT-guided transthoracic lung biopsy in the work-up of screen-detected lung nodules, it is imperative to know how safe the procedure is. We conducted this meta-analysis to 1) determine the complication rate, and 2) identify risk factors for complications of CT-guided core biopsy and FNA.

\section{Materials and methods}

This study was conducted according to the PRISMA guidelines for systematic reviews and meta-analyses [10].

\section{Search strategy and study selection}

A literature research was performed from January 2000 to August 21, 2015, on PubMed, Embase, Web of Science, and the Cochrane Library using variations of the combination of the following search terms: (biopsy OR FNA) AND (transthoracic OR CT-guided) AND (lung cancer) AND CT. Please see e-Table 1 for the set of search terms per database. After screening title and abstract, two reviewers (W.H., G.J.) evaluated the full text of the remaining articles, with disagreements resolved by consensus.

Inclusion criteria were: (a) reporting of complications of at least 50 procedures; (b) differentiation in complications between core biopsy and FNA if both techniques were used; (c) the study was not a subset of patients from other included studies; (d) adequate complication monitoring. Complication monitoring was considered adequate if directly following the procedure a CT scan was acquired, plus a CT scan or chest radiograph 2 to $4 \mathrm{~h}$ after the procedure. Studies were excluded during screening if they clearly addressed a different topic, were case reports, conference abstracts, reviews or editorials, or if they were not published in English.

A standardized extraction form was used to collect the characteristics of the study regarding patients, nodules, procedures and complications, and how complication monitoring was performed. Two authors (W.H., G.J.) independently extracted these data, with disagreement resolved by consensus. The database was split according to the biopsy method, and all analyses were performed separately for core biopsy and FNA.

The methodological quality of the studies was assessed using the Newcastle-Ottawa Scale for nonrandomized studies, with results in a score of 0 to 9 [11]. Two authors (W.H., G.J.) independently scored the studies, with disagreement resolved by consensus.

Complications were classified as minor or major according to the Society of Interventional Radiology (SIR) Guidelines [12]. Minor complications consisted of pneumothorax without need for intervention, ground glass opacity around the target diagnosed as pulmonary hemorrhage, and transient hemoptysis. Major complications consisted of pneumothorax requiring intervention, hemothorax, air embolism, needle tract seeding, and death. Intervention was defined as treatment consequences (manual aspiration, chest tube placement, or pain control) or hospital admission. For each study the number of (major) complications was determined as the sum of all reported (major) complications. If the complications for different subgroups were reported, the number of (major) complications was determined per subgroup.

Study-specific risk factors for overall complications and for major complications that were examined are listed in Table 1.

\section{Data analysis}

Heterogeneity in the overall complication rate between studies was tested and quantified using the $I^{2}$ index [13]. $I^{2}$ values of $0,25,50$, and $75 \%$ were defined as no, low, moderate, and high heterogeneity, respectively. To identify sources of heterogeneity, the effect of potential risk factors on between-study heterogeneity was investigated. The $\mathrm{R}^{2}$ equivalent was determined to express the true variance explained by the model, as a proportion of the total true variance. The risk of publication bias was visually assessed with funnel plots of major complication rate against the sample size of the individual studies.

Pooled complication rates for core biopsy and FNA were calculated using the random-effects model, weighted by the inverse variance of the studies, under the assumption of heterogeneity. Across subgroups, a common among-study variance component was assumed, and subgroups were combined 
Table 1 Study-specific characteristics examined as risk factors for (major) complications

\begin{tabular}{|c|c|}
\hline Potential risk factor & Explanation \\
\hline Mean nodule size & Greatest axial cross section of lesion (mm) \\
\hline \multirow[t]{2}{*}{ Mean nodule depth } & Distance skin-lesion (mm) \\
\hline & Distance pleura-lesion (mm) \\
\hline Mean number of biopsies & Number of biopsy samples acquired per procedure \\
\hline Use of coaxial needle & - \\
\hline Biopsy needle diameter & When using coaxial needle, the coaxial needle diameter was used, as this is the outer diameter $(\mathrm{mm})$ \\
\hline Use of CT-fluoroscopy & - \\
\hline Use of biopsy site down technique & $\begin{array}{l}\text { Post-procedural repositioning of patients with the biopsy site facing downwards in an effort to reduce } \\
\text { complication rate }\end{array}$ \\
\hline Presence on-site cytopathology & - \\
\hline Mean procedural time & - \\
\hline Number of operators & - \\
\hline Study size & - \\
\hline Malignancy rate & Ratio of procedures in which the lesion was diagnoses as malignant by CT-guided biopsy of FNA \\
\hline Operator experience & $\begin{array}{l}\text { If an operator experience range was mentioned, the minimal mean operator experience was determined } \\
\text { (i.e. four operators with } 5-10 \text { years experience resulted in a mean of } 6.25 \text { years) }\end{array}$ \\
\hline Institute frequency & $\begin{array}{l}\text { If all procedures were performed consecutively or with a negligible number of excluded cases }(<10 \%) \text {, and } \\
\text { the inclusion start and end dates were reported, the frequency at which the procedure was performed at the } \\
\text { institute was determined. A distinction was made between high volume centres, with one or more } \\
\text { procedures per week, and low volume centres, less than one procedure per week. }\end{array}$ \\
\hline
\end{tabular}

using a fixed effect model. Forest plots were made for major complications and for all types of complications separately. Differences in complication rate between core biopsy and FNA procedures were assessed using regression analysis. All recorded study, patient, nodule, and procedural characteristics as listed in Table 1 were analyzed as potential risk factors for overall complications and for major complications in regression analysis. Correlations with significance level of $p>0.10$ are presented with odds ratio $(\mathrm{OR})$ and $95 \%$ confidence interval $(95 \% \mathrm{CI})$. Statistical significance was set at $p<0.05$. All statistical analyses were conducted with Comprehensive Meta-Analysis (CMA, version 3.2.070).

\section{Results}

Figure 1 shows the PRISMA flow diagram. Thirty-two included studies reported complications of core biopsy and 17 of FNA. Three studies reported complications of both biopsy techniques. Tables $2[7,8,14-39]$ and $3[7,8,40-53]$ show the study characteristics, complication rates, NOS scores, and forest plots for major complications of the studies for core biopsy and FNA, respectively. Forest plots for all types of complications separately can be found in e-Tables 2-9. The median NOS scores of core biopsy and FNA studies were 8 and 7 out of 9 , respectively ( $p=0.917$ ). The case control studies $(n=27)$ scored least points for representativeness of cases (19/27) and for comparability of cases and controls (20/54).
The cohort studies $(n=18)$ scored least points for comparability of cohorts (26/36). Tables 3 and 4 summarizes the study, patient, nodule, and procedural characteristics of the included studies.

The heterogeneity between studies was high; for core biopsy $\mathrm{I}^{2}=93.74 \%(\mathrm{Q}$-value $606.5, \mathrm{df}(\mathrm{Q})=38, p<0.001)$ and for FNA I ${ }^{2}=95.3 \%$ (Q-value 362.3, df $(\mathrm{Q})=17, p<0.001$ ). For core biopsy no sources of heterogeneity were identified. For FNA, needle diameter and nodule size were sources of

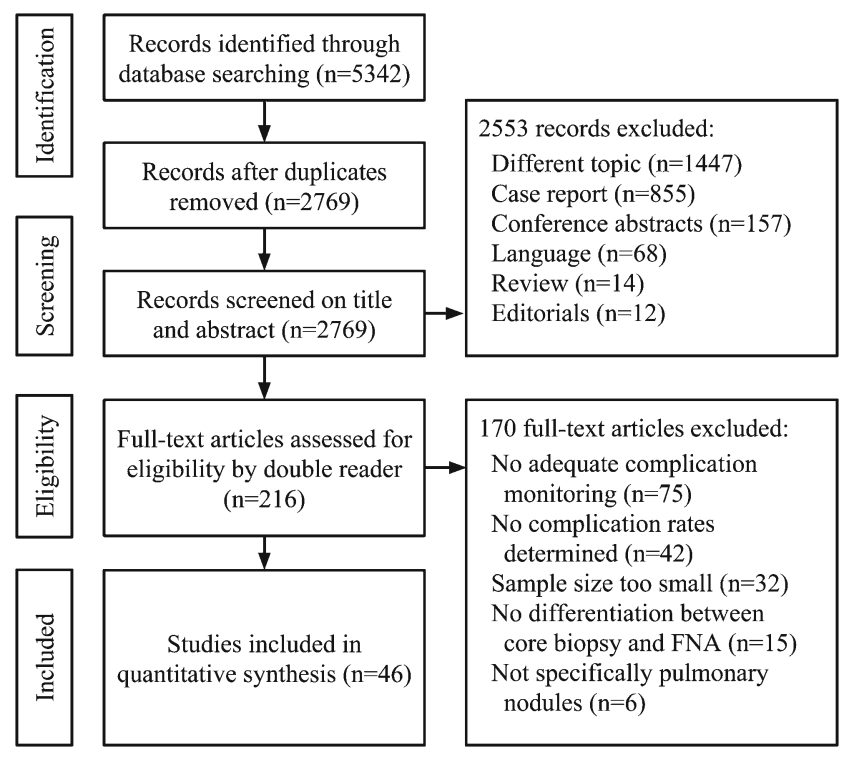

Fig. 1 PRISMA flow chart of article selection process 
Table 2 Characteristics, complication rates, and forest plot for major complications from included studies for core biopsy

\begin{tabular}{|c|c|c|c|c|c|c|c|c|c|c|c|c|c|c|c|}
\hline \multirow[b]{2}{*}{ Study } & \multirow[b]{2}{*}{ Complication monitoring } & \multirow[b]{2}{*}{ Study specifics } & \multirow{2}{*}{$\begin{array}{l}\text { Nr. of core } \\
\text { biopsy } \\
\text { procedures }\end{array}$} & \multirow[b]{2}{*}{$\begin{array}{l}\text { Biopsy } \\
\text { needle }\end{array}$} & \multirow{2}{*}{$\begin{array}{l}\text { Lesion } \\
\text { diam. } \\
(\mathrm{mm})\end{array}$} & \multicolumn{4}{|c|}{ Complication rates } & \multirow[b]{2}{*}{$\begin{array}{l}\text { NOS } \\
\text { Score }\end{array}$} & \multirow{2}{*}{$\begin{array}{l}\text { Major } \\
\text { Compli- } \\
\text { cations }\end{array}$} & \multirow{2}{*}{\multicolumn{4}{|c|}{ 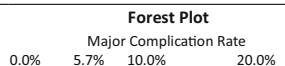 }} \\
\hline & & & & & & PNX & $\begin{array}{c}\text { PNX } \\
\text { int }\end{array}$ & $\begin{array}{l}\text { Pulm. } \\
\text { Hem. }\end{array}$ & $\begin{array}{c}\text { Hemop- } \\
\text { tysis }\end{array}$ & & & & & & \\
\hline Anzidei et al ${ }^{74}$ (2015) & CT Oh \& CXR 4h & & 342 & $18 \mathrm{~g}$ & 36 & 45.3 & & N.S. & N.S. & 8 & $47 / 342$ & & & 10 & \\
\hline Besir et al ${ }^{14}(2011)$ & CT Oh \& CXR 2h & & 102 & $18 \mathrm{~g}$ & 36 & $15.7 \%$ & $8.8 \%$ & N.S. & $2.0 \%$ & 7 & $9 / 102$ & & - & & \\
\hline Billich et a $1^{15}(2008)$ & CT Oh \& CXR 2h & $\begin{array}{l}\text { Control } \\
\mathrm{NaCl} \text { plug }\end{array}$ & $\begin{array}{l}70 \\
70\end{array}$ & $16 \mathrm{~g} \mathrm{cx}$ & $\begin{array}{l}30 \\
29\end{array}$ & $\begin{array}{r}8.6 \% \\
34.3 \%\end{array}$ & $\begin{array}{c}1.4 \% \\
11.4 \%\end{array}$ & $\begin{array}{l}4.3 \% \\
2.9 \%\end{array}$ & $\begin{array}{l}\text { N.S. } \\
\text { N.S. }\end{array}$ & 9 & $\begin{array}{l}1 / 70 \\
7 / 70\end{array}$ & - & & - & -1 \\
\hline Bozbas et al ${ }^{16}(2010)$ & CT $0 \mathrm{~h} \& \mathrm{CT} 1 \mathrm{~h}$ & & 270 & $19 \mathrm{gcx}$ & 40 & $21.9 \%$ & $8.1 \%$ & $3.3 \%$ & $0.7 \%$ & 6 & $22 / 270$ & & - & $\longrightarrow$ & \\
\hline Braak et al $^{17}(2012)$ & CT Oh \& CXR 2h & CT-fluoroscopy & 84 & $17 \mathrm{~g} \mathrm{cx}$ & 33 & $16.7 \% 0$ & $.0 \% .1 \%$ & N.S. & $1.2 \%$ & 7 & $6 / 84$ & & & & \\
\hline Branden et a $\mathrm{a}^{70}$ (2014) & CT Oh \& CXR 4h & & 380 & $16 \mathrm{~g} \mathrm{cx}$ & N.S. & $36.1 \%$ & $5.8 \%$ & $10.8 \%$ & N.S. & 9 & $22 / 380$ & $\mapsto$ & 二 & & \\
\hline Chakrabarti et al $\left.\right|^{19}$ (2009) & CT Oh \& CXR 3h & & 134 & $19 \mathrm{~g} \mathrm{cx}$ & N.S. & $23.9 \%$ & $3.7 \%$ & $3.7 \%$ & $0.7 \%$ & 5 & $5 / 134$ & $\bullet$ & & & \\
\hline Lim et $\mathrm{al}^{20}$ (2014) & CT Oh \& CXR 4h & $\begin{array}{l}\text { No pleural contact } \\
\text { Pleural contact }\end{array}$ & $\begin{array}{l}249 \\
132\end{array}$ & $20 \mathrm{gcx}$ & N.S. & $\begin{array}{l}37.8 \% \\
15.2 \%\end{array}$ & $\begin{array}{l}2.8 \% \\
0.0 \%\end{array}$ & N.S. & N.S. & 9 & $\begin{array}{l}7 / 249 \\
0 / 132\end{array}$ & $\bullet$ & & & \\
\hline Hanninen et $\mathrm{al}^{21}$ (2001) & CT Oh \& CXR 4h & & 79 & $20 \mathrm{~g}$ & N.S. & $24.1 \%$ & $5.1 \%$ & $29.1 \%$ & $0.0 \%$ & 7 & $4 / 79$ & $\longmapsto$ & & $\longrightarrow$ & \\
\hline Heck et al ${ }^{22}$ (2006) & CT Oh \& CXR 2h & $\begin{array}{l}\text { CT-fluoroscopy } \\
\text { conventional }\end{array}$ & $\begin{array}{l}57 \\
42\end{array}$ & $17 \mathrm{~g} \mathrm{cx}$ & $\begin{array}{l}25 \\
30\end{array}$ & $\begin{array}{l}26.3 \% \\
38.1 \%\end{array}$ & $\begin{array}{l}7.0 \% \\
9.5 \%\end{array}$ & N.S. & N.S. & 7 & $\begin{array}{l}4 / 57 \\
4 / 42\end{array}$ & & & & \\
\hline Hiraki et al $^{23}(2010)$ & CT $0 \mathrm{~h} \&$ CXR 3h & CT-fluoroscopy & 1098 & $19 \mathrm{gcx}$ & 23 & $42.3 \%$ & $5.0 \%$ & N.S. & N.S. & 9 & $55 / 1098$ & & & & \\
\hline Khan et al $\mathrm{al}^{24}(2008)$ & CT Oh \& CXR 4h & & 135 & $18 \mathrm{~g}$ & N.S. & $17.0 \%$ & $2.2 \%$ & $27.4 \%$ & $6.7 \%$ & 8 & $3 / 135$ & $\mapsto$ & 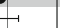 & & \\
\hline Kim et al ${ }^{75}(2008)$ & CT Oh \& CXR 3h & & 50 & $18-20 \mathrm{~g}$ & 19 & $20.0 \%$ & $2.0 \%$ & $26.0 \%$ & $14.0 \%$ & 6 & $1 / 50$ & $\mapsto$ & & $\longrightarrow$ & \\
\hline Kinoshita et $\mathrm{al}^{26}$ (2006) & CT Oh \& CXR 2h \& 24h & $\begin{array}{l}\text { Control } \\
\text { Puncture side down }\end{array}$ & $\begin{array}{c}99 \\
147\end{array}$ & $20 \mathrm{~g}$ & $\begin{array}{l}21 \\
18\end{array}$ & $\begin{array}{l}53.5 \% \\
12.9 \%\end{array}$ & $\begin{array}{c}16.2 \% \\
2.7 \%\end{array}$ & $\begin{array}{l}19.2 \% \\
12.9 \%\end{array}$ & $\begin{array}{l}1.0 \% \\
2.0 \%\end{array}$ & 8 & $\begin{array}{l}16 / 99 \\
4 / 147\end{array}$ & $\mapsto$ & $\rightarrow$ & & \\
\hline Kuban et al ${ }^{60}(2015)$ & CT Oh \& CXR 3h & & 1002 & $18-19 \mathrm{~g} \mathrm{cx}$ & N.S. & $30.0 \%$ & $16.0 \%$ & N.S. & N.S. & 6 & $156 / 1002$ & & & - & \\
\hline Laurent et $\mathrm{al}^{7}(2000)$ & CT Oh \& CXR 4-6h & & 98 & $18 \mathrm{~g} \mathrm{cx}$ & 35 & $15.3 \%$ & $2.0 \%$ & $28.6 \%$ & $4.1 \%$ & 9 & $2 / 98$ & $\mapsto$ & 二 & & \\
\hline Laurent et al ${ }^{27}(2000)$ & CT Oh \& CXR 4h & $\begin{array}{l}\emptyset<2 \mathrm{~cm} \\
\varnothing>=2 \mathrm{~cm}\end{array}$ & $\begin{array}{c}67 \\
135\end{array}$ & $19 \mathrm{gcx}$ & $\begin{array}{l}16 \\
49\end{array}$ & $\begin{array}{l}14.9 \% \\
16.3 \%\end{array}$ & $\begin{array}{l}3.0 \% \\
0.7 \%\end{array}$ & $\begin{array}{l}43.3 \% \\
14.1 \%\end{array}$ & $\begin{array}{l}6.0 \% \\
5.2 \%\end{array}$ & 9 & $\begin{array}{c}2 / 67 \\
1 / 135\end{array}$ & $\longmapsto$ & & $\rightarrow$ & \\
\hline Loubeyre et $\mathrm{al}^{28}(2005)$ & CT Oh \& CXR 4h & & 76 & $17 \mathrm{~g} \mathrm{cx}$ & N.S. & $15.8 \%$ & $1.3 \%$ & $18.4 \%$ & $7.9 \%$ & 8 & $1 / 76$ & $\omega$ & $\rightarrow$ & & \\
\hline Maataoui et al $^{29}$ (2012) & CT Oh \& CXR 4h & & 135 & $18 \mathrm{~g}$ & N.S. & N.S. & $2.2 \%$ & $6.7 \%$ & N.S. & 6 & $3 / 135$ & $\mapsto$ & & & \\
\hline Mendiratta-Lala et al ${ }^{30}$ (2014) & CT/CTf Oh \& CXR 2-4h & CT-fluoroscopy & 169 & $19 \mathrm{~g}$ & 24 & $40.8 \%$ & $8.3 \%$ & N.S. & N.S. & & $17 / 169$ & & $\longmapsto$ & 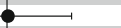 & \\
\hline Montaudon et al $\left.\right|^{31}$ (2004) & CT Oh \& CXR 4h & & 605 & $19 \mathrm{gcx}$ & N.S. & $17.4 \%$ & $0.5 \%$ & $20.2 \%$ & $4.0 \%$ & 7 & $5 / 605$ & - -1 & & & \\
\hline Patel et al $\mathrm{a}^{32}$ (2014) & CT Oh \& CXR 2h & & 174 & $19 \mathrm{~g} \mathrm{cx}$ & 27 & $36.2 \%$ & $16.7 \%$ & N.S. & N.S. & 9 & $29 / 174$ & & & $\bullet$ & $\longrightarrow$ \\
\hline Prosch et $\mathrm{al}^{33}$ (2012) & $\begin{array}{l}\text { CT Oh \& CXR 2h } \\
\& \text { CXR 24h }\end{array}$ & $\begin{array}{l}\text { CT-fluoroscopy } \\
\text { Conventional }\end{array}$ & $\begin{array}{l}124 \\
132\end{array}$ & $17 \mathrm{gcx}$ & $\begin{array}{l}26 \\
29\end{array}$ & $\begin{array}{l}29.8 \% \\
32.6 \%\end{array}$ & $\begin{array}{c}4.0 \% \\
12.9 \%\end{array}$ & $\begin{array}{l}50.8 \% \\
54.5 \%\end{array}$ & $\begin{array}{l}1.6 \% \\
0.0 \%\end{array}$ & 7 & $\begin{array}{c}5 / 124 \\
17 / 132\end{array}$ & $\bullet$ & & & \\
\hline Rotolo et al $\mathrm{l}^{76}$ (2015) & CT Oh \% CXR 4h & CT-fluoroscopy & 201 & $20 \mathrm{gcx}$ & 17 & $26.7 \%$ & $9.4 \%$ & $18.6 \%$ & $0.5 \%$ & 9 & $19 / 201$ & & & & \\
\hline Satoh et al ${ }^{34}(2005)$ & CT Oh \& CXR 2h & & 65 & $18-20 \mathrm{~g}$ & 34 & $27.7 \%$ & $1.5 \%$ & $23.1 \%$ & $0.0 \%$ & 7 & $2 / 65$ & $\longmapsto$ & & $\neg$ & \\
\hline Schoth et $\mathrm{al}^{35}(2010)$ & CT Oh \& CXR 2h \& CXR 4h & & 36 & $18 \mathrm{~g}$ & 29 & $27.8 \%$ & $5.6 \%$ & N.S. & $2.8 \%$ & 9 & $2 / 36$ & $\longmapsto$ & & & \\
\hline Tachibana et al ${ }^{36}$ (2013) & CT Oh \& CXR 2-3h & $\begin{array}{l}\text { No on-site cytology } \\
\text { On-site cytology }\end{array}$ & $\begin{array}{c}98 \\
172\end{array}$ & $18 \mathrm{~g}$ & $\begin{array}{l}33 \\
32\end{array}$ & $\begin{array}{l}34.7 \% \\
20.3 \%\end{array}$ & $\begin{array}{c}14.3 \% \\
2.9 \%\end{array}$ & N.S. & $\begin{array}{l}4.1 \% \\
2.9 \%\end{array}$ & 9 & $\begin{array}{l}14 / 98 \\
5 / 172\end{array}$ & $\bullet$ & & & \\
\hline Tuna et $\mathrm{al}^{8}$ (2013) & CT 0h \& CXR 2-5h & & 83 & $18 \mathrm{~g}$ & N.S. & $8.4 \%$ & $4.8 \%$ & N.S. & N.S. & 8 & $4 / 83$ & $\longmapsto$ & & $\longrightarrow$ & \\
\hline Yamagami et al ${ }^{77}$ (2006) & CT Oh \& CXR 3h & CT-fluoroscopy & 388 & $18-21 \mathrm{~g}$ & 23 & $34.3 \%$ & $18.6 \%$ & N.S. & N.S. & 7 & $72 / 388$ & & & $\longmapsto$ & $\longrightarrow$ \\
\hline Yamauchi et al $\mathrm{I}^{78}$ (2011) & CT Oh \& CXR 3h & CT-fluoroscopy & 90 & $18 \mathrm{~g}$ & 17 & $15.6 \%$ & $0.0 \%$ & N.S. & $14.4 \%$ & 6 & $0 / 90$ & & $\hookrightarrow$ & & \\
\hline Yeow et al ${ }^{79}(2004)$ & CT Oh \& CXR 4h & & 660 & $16-20 \mathrm{~g} \mathrm{cx}$ & N.S. & $23.5 \%$ & $2.1 \%$ & $30.5 \%$ & $3.9 \%$ & 9 & $14 / 660$ & $\bullet$ & & & \\
\hline Yildirim et al ${ }^{39}$ (2009) & CT $0 \mathrm{~h} \& \mathrm{CT} 1 \mathrm{~h}$ & & 225 & $19 \mathrm{~g} \mathrm{cx}$ & 41 & $26.2 \%$ & $7.6 \%$ & $12.9 \%$ & $12.0 \%$ & 9 & $17 / 225$ & & & $\longrightarrow$ & \\
\hline Total & & & & & & & & & & & & & & & \\
\hline
\end{tabular}

$P N X$, pneumothorax; PNX int, pneumothorax requiring intervention; NOS, Newcastle-Ottawa Scale; N.S., not specified; $g$, gauge; $c x$, coaxial needle; In the forest plot the major complication rate with $95 \% \mathrm{CI}$ is plotted, the size of the circles represents the weight of each individual (sub) study as assigned by the random effects model

heterogeneity, explaining 17 and $22 \%$ of between-study variance, respectively. The funnel plots are shown in Figs. 2, 3, and 4 showing no indication of publication bias.

Table 5 shows the pooled complication rates of core biopsy and FNA, with respective odds ratios. Core biopsy had an overall complication rate of $38.8 \%$ (95 \% CI: 34.3-43.5\%), versus $24.0 \%$ (95 \% CI: 18.2-30.8\%) for FNA $(p<0.001)$. Respective rates for major complications were $5.7 \%(95 \%$
CI: $4.4-7.4 \%)$ and $4.4 \%$ (95\% CI: $2.7-7.0 \%)(p=$ n.s. $)$. In total, only five studies [30, 31, 34, 44, 50] reported cases of hemothorax; no pooled hemothorax rate could reliably be determined. Needle tract seeding, air embolism, and death were not reported in the included studies. The overall pneumothorax rate, the pulmonary haemorrhage rate, and the hemoptysis rate of FNA procedures were significantly lower than those of core biopsy procedures.

Table 3 Characteristics, complication rates, and forest plot for major complications from included studies for FNA

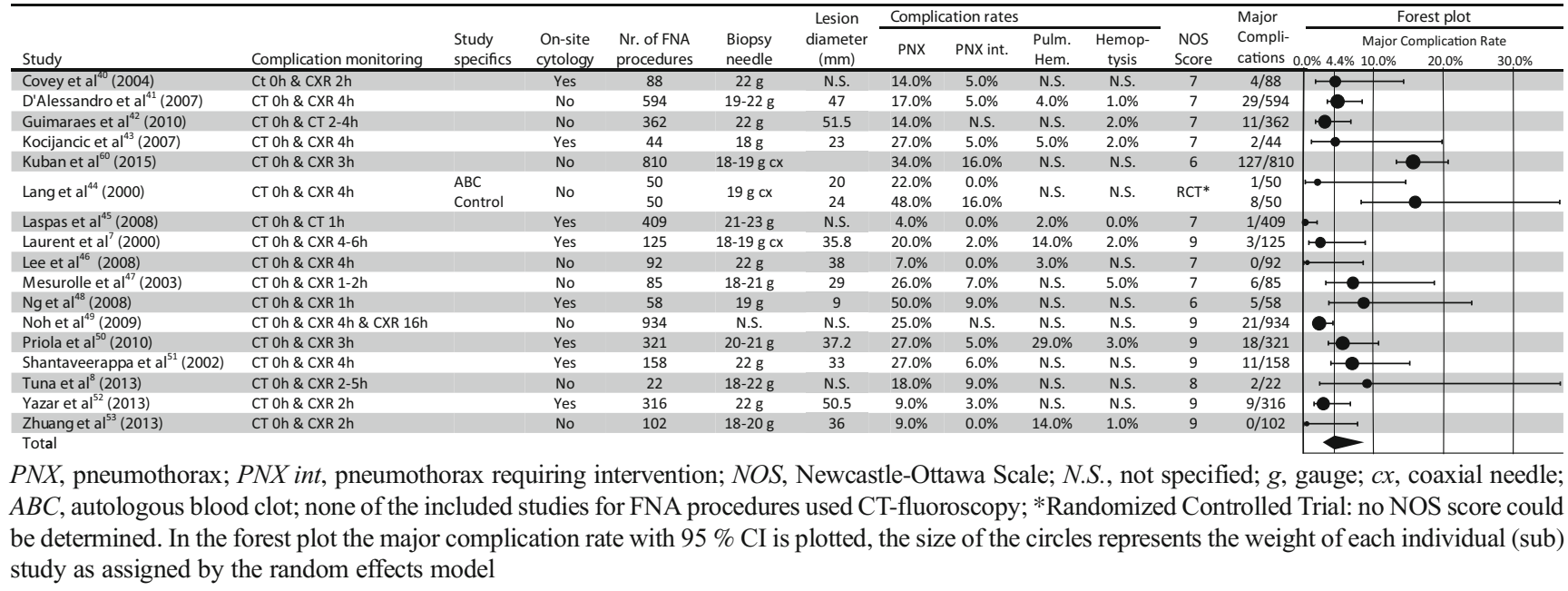


Table 4 Study, procedural, patient, and nodule characteristics of included studies

\begin{tabular}{lll}
\hline & Core biopsy $(n=32)$ & FNA $(n=17)$ \\
\hline Quality & Mean (SD) 7.6 (1.2) & Mean (SD) 7.7 (1.1) \\
& Median (range) 8 & $\begin{array}{l}\text { Median (range) } 7 \\
(5-9)\end{array}$ \\
Procedures $(n)$ & 8,133 & 4,620 \\
Needle gauge & $18.2(1.2)$ & $21.3(1.7)$ \\
Use of coaxial needle & $25 / 29$ & $4 / 16$ \\
Use of biopsy device & $26 / 29$ & N.A. \\
Use of CT-fluoroscopy & $10 / 29$ & $0 / 16$ \\
Gender & & \\
$\quad$ Male (n) & 4,303 & 1,792 \\
$\quad$ Female (n) & 2,192 & 649 \\
Patient age (years) & $64.4(2.9)$ & $62.3(3.8)$ \\
Pleural passes $(n)$ & $1.1(0.4)$ & 1.5 \\
Nodule diameter (mm) & $27.9(7.8)$ & $41.4(10.0)$ \\
Distance skin-lesion (mm) & $53.2(13.3)$ & $48.0(6.0)$ \\
Traversed lung (mm) & $16.6(6.6)$ & $14.1(7.3)$ \\
Procedure time (min) & $32(5)$ & N.S. \\
Operator experience (years) & $10.1(4.0)$ & $8.0(2.5)$ \\
\hline
\end{tabular}

Data are presented as number of studies or means with standard deviation. Means are weighted by number of procedures. N.A. Not available

\section{Risk factors for complications}

Table 6 lists all risk factors for complications with a $p$-value $<0.20$. For FNA procedures, larger needle diameter was a risk factor for overall complications, with an odds ratio of 0.70 (95 \% CI: $0.55-0.89 \% ; p=0.004$ ) per gauge. When analyzing the needle diameter categorically, an FNA needle gauge of 22 or higher resulted in decreased odds of overall complications

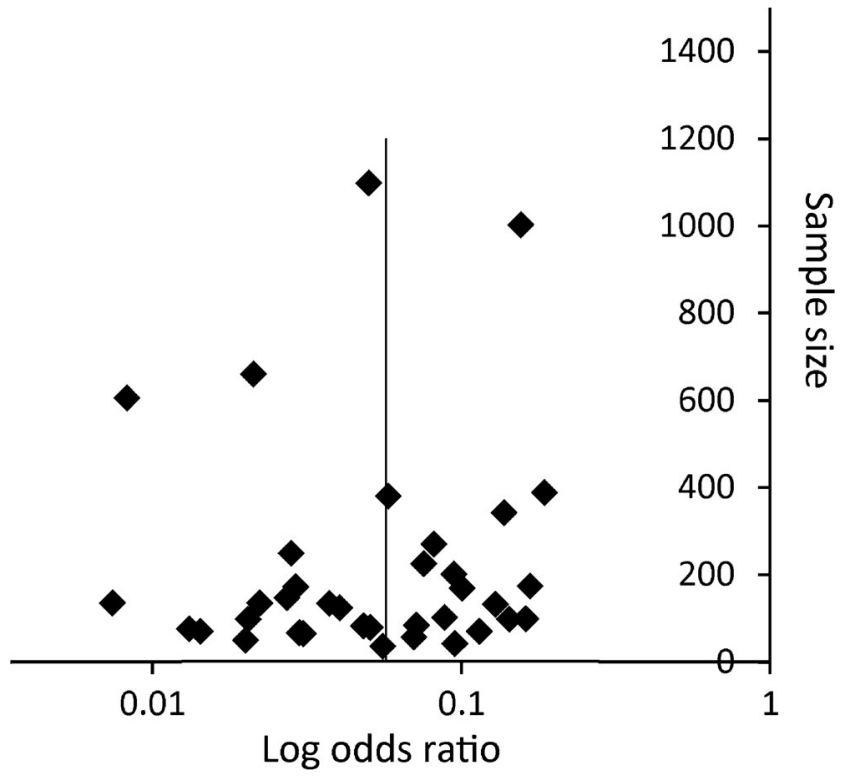

Fig. 2 Funnel plot of major complications of CT-guided core biopsy

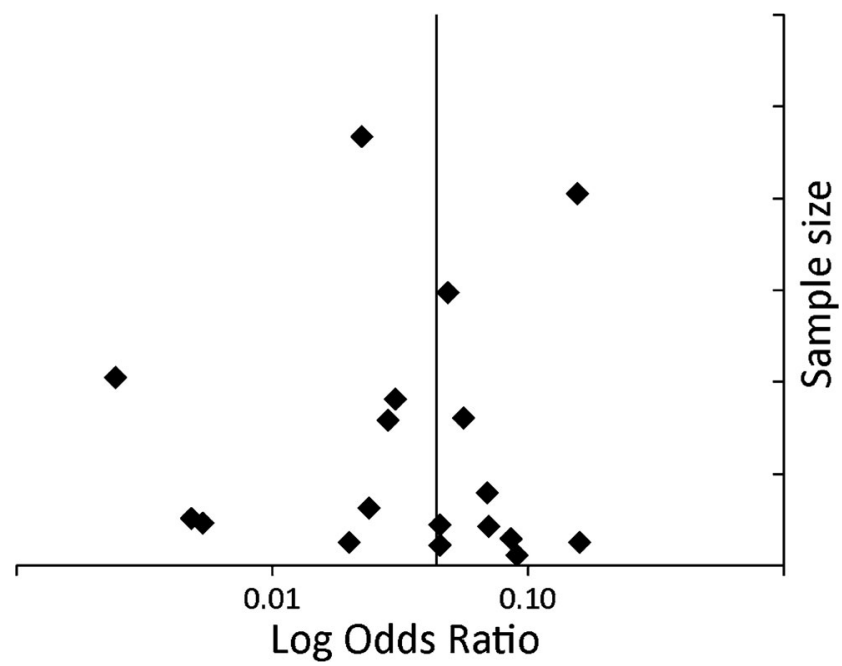

Fig. 3 Funnel plot of major complications of CT-guided FNA

of 0.30 (95\% CI: $0.15-0.59 \% ; p<0.001$ ) compared to lower needle gauges. Figure 2 shows a scatter plot of the mean needle size in FNA studies against the complication rate. Increased mean lesion diameter decreased the risk of major complications (OR: 0.97 per mm; $95 \%$ CI: 0.95-0.99 \%; $p=0.017$ ), and increased traversed lung parenchyma increased the risk of major complication (OR: 1.05 per mm; $95 \%$ CI: $1.00-1.11 \% ; p=0.035)$. The meta-analysis of core biopsies did not reveal significant risk factors for overall complications or for major complications.

\section{Discussion}

This meta-analysis determined the complication rate of CTguided core biopsy and FNA procedures and identified risk factors for complications. For CT-guided core biopsy the pooled rate of pneumothorax was $25.3 \%$, of pneumothorax requiring intervention $5.6 \%$, of pulmonary haemorrhage $18.0 \%$, and of hemoptysis $4.1 \%$. For FNA procedures these rates were lower, $18.8,4.3,6.4$, and $1.7 \%$, respectively. This difference was significant for all minor complications. For FNA, larger needle diameter, smaller lesion size, and increased traversed lung parenchyma were risk factors for complications.

To our knowledge, no prior meta-analysis has studied the complication rate of CT-guided lung biopsy. Two large studies based on multi-centre procedures have been published. Wiener et al. [54] estimated the complications rate of CTguided lung biopsy by analyzing two North American databases containing 15,865 procedures and found that pneumothorax occurred in $15.0 \%$, pneumothorax requiring chest tube in $6.6 \%$, and pulmonary hemorrhage in $1.0 \%$. No distinction was made between core biopsy and FNA. Tomiyama et al. [55] published a survey of severe complications based on 9 , 783 CT-guided lung biopsies in Japan and found 
Fig. 4 Scatter plot and regression line with $95 \%$ confidence interval of mean needle diameter in relation to overall complication rate in FNA procedures. The size of the circles represents the relative weight of the study as assigned by the random effects model

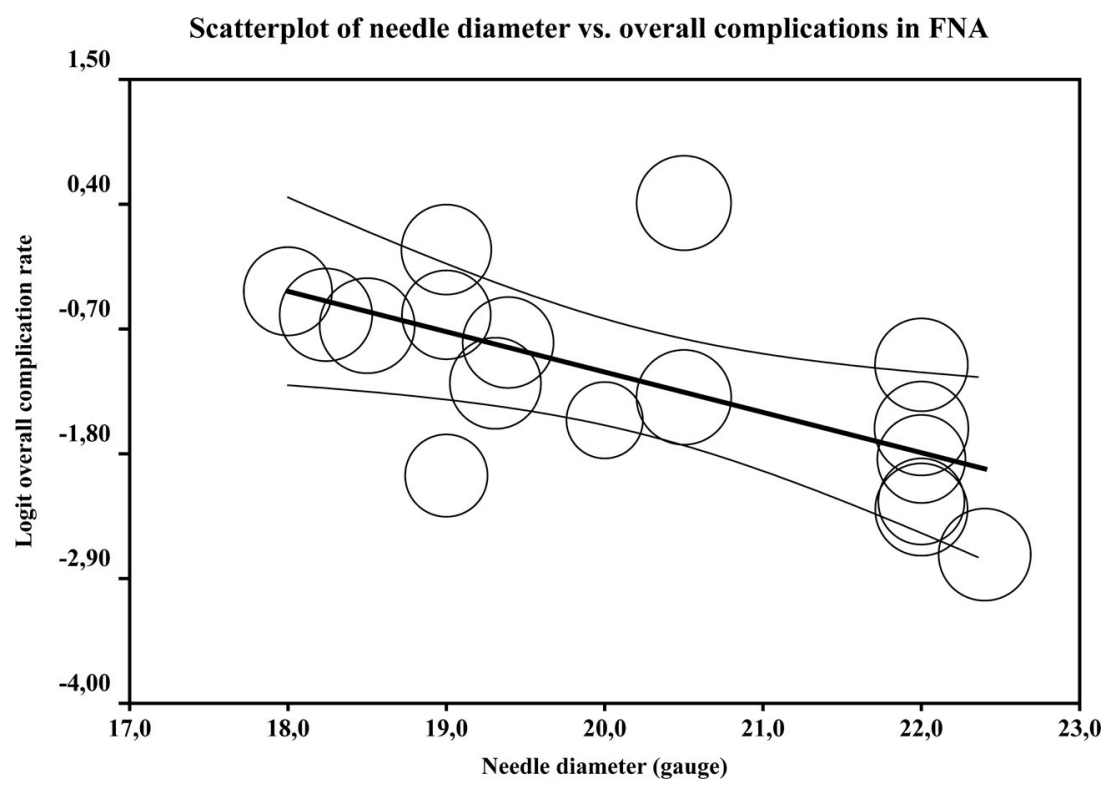

pneumothorax in $35 \%$. These results are quite discrepant. Neither of these studies was included in this meta-analysis, because they did not meet the inclusion criteria. In Quality Improvement Guidelines for Percutaneous Needle Biopsy, the SIR and ACR published an estimated pneumothorax rate of $12-45 \%$ and a chest tube placement rate of 2-15\% [56]. Again, this is a wide range, without differentiation between core biopsy and FNA. However, our estimates of complication rate are approximately in the centre of their estimated range.

Hemothorax rate could not be estimated reliably, because it was reported in only six studies. Other rare major complications such as needle tract seeding, air embolism and death were not reported by any of the included studies. Nonincluded studies reported a range of $0.02-0.4 \%$ for air embolism [55, 57], 0.012-0.061\% for needle tract seeding [55, 58], and $0.16 \%$ for death [59]. In our selected studies $(12,753$ procedures in total) these complications could have been expected to occur, but such results are probably not as likely to be published. Therefore, an underrepresentation of these very rare and major complications is likely to exist in this metaanalysis.

Comparing core biopsy with FNA is not straightforward. Core biopsy and FNA have their own advantages when used to diagnose lung lesions. Still, overall, complications occurred less often in FNA procedures (OR: 0.50; 95 \% CI: $0.35-$ $0.73 \%$ ). For major complications this correlation was not significant, although a similar trend was visible in favour of FNA. Included studies that compared FNA with core biopsy $[7,8,60]$ did not find significant differences in complication rate, and in a systematic review comparing FNA with core biopsy in lung cancer diagnosis, Yao et al. [9] reported inconsistent results concerning complication rates.

In this study, a smaller lesion size and an increased distance traversed through lung parenchyma were found as risk factors for major complications in case of FNA. Patient and nodule characteristics most often mentioned as risk factors are older age, presence of emphysema, smaller lesion size, increased lesion depth, non-pleural contact, and smaller pleural-needle angle [38, 39, 61-63]. However, in most included studies

Table 5 Pooled complication rates of CT-guided transthoracic lung biopsy

\begin{tabular}{|c|c|c|c|c|}
\hline & \multicolumn{2}{|c|}{ Complication rates (95\% confidence intervals) } & \multirow[t]{2}{*}{ Odds ratio $^{\mathrm{a}}$} & \multirow[t]{2}{*}{$p$-value } \\
\hline & Core biopsy & FNA & & \\
\hline Pneumothorax & $25.3 \%(22.2-28.6 \%)$ & $18.8 \%(14.6-23.9 \%)$ & $0.69(0.50-0.96)$ & 0.027 \\
\hline Pneumothorax intervention & $5.6 \%(4.3-7.3 \%)$ & $4.3 \%(2.7-7.0 \%)$ & $0.76(0.48-1.37)$ & 0.430 \\
\hline Pulmonary haemorrhage & $18.0 \%(13.4-23.8 \%)$ & $6.4 \%(2.5-15.2 \%)$ & $0.33(0.15-0.72)$ & 0.005 \\
\hline Hemoptysis & $4.1 \%(2.8-6.1 \%)$ & $1.7 \%(0.9-3.1 \%)$ & $0.38(0.17-0.85)$ & 0.019 \\
\hline Overall complications & $38.8 \%(34.3-43.5 \%)$ & $24.0 \%(18.2-30.8 \%)$ & $0.50(0.35-0.73)$ & $<0.001$ \\
\hline Major complication & $5.7 \%(4.4-7.4 \%)$ & $4.4 \%(2.7-7.0 \%)$ & $0.80(0.48-1.36)$ & 0.416 \\
\hline
\end{tabular}

${ }^{\mathrm{a}}$ Core biopsy is reference 
Table 6 Risk factors for complications and major complications for CT-guided transthoracic core biopsy and FNA of lung lesions

\begin{tabular}{lcllr}
\hline & Studies (n) & Procedures (n) & Odds ratio (95 \% CI) & $p$-value \\
\hline Core biopsy: Overall complications & & & & \\
$\quad$ Coaxial needle & 32 & 8,133 & $1.37(0.88-2.12)$ & 0.164 \\
$\quad$ Mean lesion size & 32 & 8,133 & $0.98(0.94-1.01)$ & 0.185 \\
$\quad$ Use of biopsy device & 32 & 8,133 & $1.44(0.91-2.27)$ & 0.115 \\
Core biopsy: Major complications & & & & \\
CT-fluoroscopy & 32 & 8,133 & $1.62(0.81-3.23)$ & 0.171 \\
Mean patient age & 32 & 8,133 & $1.09(0.98-1.21)$ & 0.124 \\
FNA: Overall complications & & & & \\
Mean needle gauge & 17 & 4,084 & $0.70(0.55-0.89)$ & 0.004 \\
Needle diameter >= 22 gauge & 17 & 4,084 & $0.30(0.15-0.59)$ & $<0.001$ \\
Mean lesion size & 12 & 2,357 & $0.97(0.93-1.00)$ & 0.073 \\
Mean number of biopsy samples & 6 & & $1.36(0.50-3.71)$ & 0.549 \\
FNA: Major complications & & & & 0.106 \\
Mean needle gauge & 17 & 4,084 & $0.82(0.64-0.96)$ & 0.172 \\
Needle diameter >= 22 gauge & 17 & 4,084 & $0.58(0.27-1.27)$ & 0.035 \\
Traversed lung (mm) & 4 & 797 & $1.05(1.00-1.11)$ & 0.146 \\
Coaxial needle & 17 & 4,084 & $1.87(0.80-4.33)$ & 0.017 \\
Lesion size (mm) & 12 & 2,357 & $0.97(0.95-0.99)$ & 0.079 \\
Number of operators & 10 & 2,496 & $1.29(0.97-1.71)$ & \\
\hline
\end{tabular}

Only potential risk factors with a significant of $p<0.20$ are listed in this table these characteristics are only reported as a mean, and complications are not stratified based on these variables. Therefore, this meta-analysis is not ideal to identify patient- and nodulespecific risk factors.

In contrast, a meta-analysis can find risk factors in studyspecific characteristics such as needle size, use of coaxial needle, number of biopsies, use of CT-fluoroscopy, on-site cytology, number of operators, operator experience, and institute frequency - factors that would be hard to identify in a singlecohort/institute, retrospective study. There was no difference in risk of complication between high and low volume centres. Also, no significant correlation between the sample size, number of biopsies, number of operators, operator experience, use of coaxial needle, CT-fluoroscopy, on-site cytology, or biopsy site down technique and (major) complication rate was found.

Only papers using CT guidance (conventional and/or CTfluoroscopy) were included in this study. Conventional CT guidance offers the advantage of a simulated $3 \mathrm{D}$ view making it easy to look along the needle path. Also, there is no ionizing radiation exposure for the operator. CT-fluoroscopy offers the advantages of a near real-time imaging feedback as the needle is being inserted. It is, however, associated with an increased patient and operator dose $[22,64,65]$. These methods can be used interchangeably, e.g. starting with conventional CT guidance and switching to CT-fluoroscopy when the lung lesion proves difficult to reach because of patient respiration. For core biopsy we found a trend that suggested CT-fluoroscopy might result in a higher major complication rate (OR: 1.62; $95 \%$ CI: $0.81-3.23 \% ; p=0.171)$. CT-fluoroscopy is generally reported to have a lower complication rate due to shorter procedure time and fewer needle passes [22, 33, 64]. However, if CT-fluoroscopy is indeed used more frequently in cases of hard-to-reach lesions, it could potentially bias the results, as it generally takes longer to sample these. Lastly, it should be noted that none of the included studies used CTfluoroscopy for FNA.

Intuitively, operator experience is thought to influence complication rate. In a large single-cohort study, Yeow et al. [38] reported operator experience as the third major risk factor for pneumothorax. In our meta-analysis only a few papers reported the operator experience (core biopsy: $n=10$; FNA: $n=3$ ). Because of the low number of studies reporting operator experience, and because only overall mean operator experience was reported (so not per operator), it was not possible to further study this potential risk factor in our meta-analysis.

The use of coaxial needles has the advantage of decreasing the number of pleural passes. However, it results in a prolonged connection with the pleura which might lead to increased parenchymal damage due to respiratory motion. Also, it increases the outer needle diameter. None of the included studies specifically investigated the effect of coaxial needles on complication rate. Two other studies did [66, 67], but found no significant correlation. In meta-regression there were trends for coaxial needles towards an increase in overall complications for core biopsy (OR: $1.37 ; 95 \%$ CI: 0.88 $2.12 \% ; p=0.164$ ), and for FNA (OR: $1.87 ; 95 \%$ CI: 0.80 $4.33 \% ; p=0.146)$, but none of these correlations were significant. 
The biopsy site down technique has been cause for some debate; although some papers report no difference in complication rate when repositioning the patient after the procedure [64], others have demonstrated a considerable reduction in pneumothorax and/or chest tube placement rate in case of patient repositioning [65]. O'Neill et al. [66] suggested that the critical factor for success is to immediately roll the patient over after biopsy, calling it rapid needle-out patient-rollover. Kim et al. [67] recently reported a significant reduction of chest tube placement in cone beam CNB in a retrospective study among 1,191 patients, using similar technique. None of the papers included in this meta-analysis, using the biopsy site down technique, mentioned to roll the patients over immediately, which is why this correlation could not be evaluated. However, Kinoshita et al. [26] have been positioning patients $(n=147)$ with the biopsy site downwards during the procedure, using a special table, after which they stayed in biopsy site down position for approximately $15 \mathrm{~min}$. They report a considerable drop in pneumothorax rate compared to the standard procedure, which also suggests that patient (re) positioning in the initial minutes after, or even during, biopsy is critical.

For overall complications in FNA, the use of larger needles was a risk factor. Per increased needle gauge, the risk decreased by $30 \%$ (OR: $0.70 ; 95 \%$ CI: $0.55-0.89 \%$ ). According to the guidelines of the SIR [56] only procedures performed with 22 or higher gauge needles should be considered fine needle aspiration. When categorized according to this definition, the use of fine needles compared to larger needles decreased the risk of complications by $70 \%$ (OR: 0.30 ; $95 \%$ CI: $0.15-0.59 \%)$. For major complications, however, needle size was not a significant risk factor. For core biopsy procedures no significant risk factors were found.

Studies were only included in this meta-analysis if they reported adequate monitoring of complications. Although that resulted in the exclusion of 75 studies, it made sure that no studies were included that underreported their complication rate. Because chest radiography has demonstrated to miss a significant number of pneumothorax cases after CT-guided lung biopsy compared to CT [68], an initial control CT scan was a requirement for inclusion. Also, at least additional chest radiography 2 to $4 \mathrm{~h}$ after the procedure was required, because studies have shown that initially covert pneumothorax detected by delayed chest radiograph sometimes does require chest tube insertion [49, 69]. Another inclusion criterion was the reporting of complications of at least 50 procedures, resulting in the exclusion of 32 studies. Excluding smaller studies may bias results, as less experienced departments can be expected to have a higher complication rate. The funnel plots of included studies show no clear asymmetry, and regression analysis showed no correlation between sample size and complication rate, so we do not expect the exclusion of small studies to have biased the results. However, since small studies were not included in the analyses, this cannot be excluded with certainty.

We investigated potential sources of heterogeneity, but much of the variance between studies could not be explained. Therefore, a random-effects model was used to pool complication rates. This makes the estimates more reliable as it favours larger studies relatively less, compared to a fixed effects model. Also, outliers do not get weighted as heavily as they otherwise would. Overall, we expect that the provided pooled complication rates are accurate estimates of actual complication rates.

This study has some limitations. It was not designed to compare specifically the complication rates of core biopsy with FNA. Most included studies only report complications of one method, so usually no controls in the same population are available. Also, although the quality of the studies included in both groups is generally high according to the NOS score, there are potential sources of bias within the studies. In the past, FNA would be preferred over core biopsy for small nodules, because core samples of high quality were considered hard to obtain. It has previously been shown that smaller lesions are more likely to result in complications, which might cause the pooled complication rates of core biopsy and FNA to be biased $[24,40]$. However, in our meta-analysis the mean lesion diameter for core biopsy was significantly smaller than for FNA procedures ( $28 \mathrm{vs} .42 \mathrm{~mm}$ ). Although lesion size was not a significant risk factor for complications of core biopsy, this difference could be a potential confounder. Another potential source of within study bias could be in the selection of sampling techniques in case additional histological subtyping is required for targeted therapy. In those cases core biopsy is often preferred, and these patients can be expected to have a higher comorbidity resulting in a higher complication rate.

Papers were only included if complications of FNA and core biopsy were presented separately. Sometimes both techniques are used in the same setting in an effort to increase the diagnostic performance, which can inadvertently lead to a higher rate of complications [70-72]. This study cannot draw conclusions as to whether or not combined usage of sampling techniques indeed increases the complication rate.

Lastly, this study could not determine the rate of complications that occur infrequently or require a long term follow-up of the patient, such as death, air embolism and needle tract seeding.

In the specific context of diagnostic work-up of lung nodules detected in CT-screening FNA should be favoured over core biopsy. This is especially the case for 22-gauge needles, with which the risk of complications decreases greatly. Also, studies have shown that diagnostic yield does not decrease when using smaller FNA needles [73], and advances in FNA cytology have enabled subtyping of lung cancer in cytological material [74].

It should be considered that a smaller lesion size is a risk factor for major complications, and that nodules detected by 
lung cancer CT-screening, needing work-up, are generally smaller in size [75]. However, factors such as younger age and less comorbidity that can be expected in screening patients will have a beneficial effect on the expected complication rate. Overall, the pooled complication rate determined in this meta-analysis cannot be assumed to be similar in screendetected nodules.

In order to compare the complications of core biopsy and FNA properly, only randomized controlled trials or even only prospective studies comparing both techniques should be included in the meta-analysis. However, randomized controlled trials comparing these techniques have not been published, and only two prospective studies compared complication rates. Therefore, well-designed randomized controlled trials would be recommended to definitively compare the safety of CT-guided lung core biopsy and FNA.

\section{Conclusion}

For CT-guided lung biopsy the overall complication rate is acceptable and the major complication rate is low. Minor complications occur more often with core biopsy compared to FNA. For major complications this difference is not significant. In cases of FNA, larger needle size is a risk factor for overall complications, and risk factors for major complications are smaller lesion size and increased traversed lung parenchyma. CT-guided lung biopsy, and particularly FNA with small needles, can be an important diagnostic tool, with a low major complication rate.

Acknowledgments The scientific guarantor of this publication is M. Oudkerk. The authors of this manuscript declare no relationships with any companies, whose products or services may be related to the subject matter of the article. The authors state that this work has not received any funding. One of the authors has significant statistical expertise. Institutional Review Board approval was not required because this meta-analysis does not involve human subjects. Methodology: retrospective, observational, performed at one institution.

Open Access This article is distributed under the terms of the Creative Commons Attribution 4.0 International License (http:// creativecommons.org/licenses/by/4.0/), which permits unrestricted use, distribution, and reproduction in any medium, provided you give appropriate credit to the original author(s) and the source, provide a link to the Creative Commons license, and indicate if changes were made.

\section{References}

1. Moyer VA (2014) Screening for lung cancer: U.S. Preventive services task force recommendation statement. Ann Intern Med 160: $330-8$
2. Kauczor H-U, Bonomo L, Gaga M et al (2015) ESR/ERS white paper on lung cancer screening. Eur Respir J 46:28-39

3. Cardella JF, Bakal CW, Bertino RE et al (1996) Quality improvement guidelines for image-guided percutaneous biopsy in adults: society of cardiovascular \& interventional radiology standards of practice committee. J Vasc Interv Radiol 7:943-6

4. Manhire A, Charig M, Clelland C et al (2003) Guidelines for radiologically guided lung biopsy. Thorax 58:920-36

5. Beslic S, Zukic F, Milisic S (2012) Percutaneous transthoracic CT guided biopsies of lung lesions; fine needle aspiration biopsy versus core biopsy. Radiol Oncol 46:19-22

6. Yeow KM, Tsay PK, Cheung YC, Lui KW, Pan KT, Chou AS (2003) Factors affecting diagnostic accuracy of CT-guided coaxial cutting needle lung biopsy: retrospective analysis of 631 procedures. J Vasc Interv Radiol 14:581-8

7. Laurent F, Latrabe V, Vergier B, Michel P (2000) Percutaneous CTguided biopsy of the lung: comparison between aspiration and automated cutting needles using a coaxial technique. Cardiovasc Intervent Radiol 23:266-72

8. Tuna T, Ozkaya S, Dirican A, Findik S, Atici AG, Erkan L (2013) Diagnostic efficacy of computed tomography-guided transthoracic needle aspiration and biopsy in patients with pulmonary disease. Oncol Targets Ther 6:1553-7

9. Yao X, Gomes MM, Tsao MS, Allen CJ, Geddie W, Sekhon H (2012) Fine-needle aspiration biopsy versus core-needle biopsy in diagnosing lung cancer: a systematic review. Curr Oncol 19:e16-27

10. Moher D, Liberati A, Tetzlaff J, Altman DG (2009) Preferred reporting items for systematic reviews and meta-analyses: the PRISMA statement. PLoS Med 6:e1000097

11. Wells GA, Shea B, O'Connell D, Peterson J, Welch V, Losos M PT. The Newcastle-Ottawa Scale (NOS) for assessing the quality of nonrandomised studies in meta-analyses. Available from: URL: http://www.ohri.ca/programs/clinical_epidemiology/oxford.asp cited 2016 Jan 4

12. Sacks D, McClenny TE, Cardella JF, Lewis CA (2003) Society of interventional radiology clinical practice guidelines. J Vasc Interv Radiol 14:S199-202

13. Higgins JPT, Thompson SG, Deeks JJ, Altman DG (2003) Measuring inconsistency in meta-analyses. BMJ 327:557-60

14. Besir FH, Altin R, Kart L et al (2011) The results of computed tomography guided tru-cut transthoracic biopsy: complications and related risk factors. Wien Klin Wochenschr 123:79-82

15. Billich C, Muche R, Brenner G et al (2008) CT-guided lung biopsy: incidence of pneumothorax after instillation of $\mathrm{NaCl}$ into the biopsy track. Eur Radiol 18:1146-52

16. Bozbas SS, Akcay S, Ergur FO, Aytekin C, Savas BS, Ozturk EF (2010) Transthoracic lung and mediastinal biopsies obtained with the Tru-Cut technique: 10 years' experience. Turkish J Med Sci 40: 495-501

17. Braak SJ, Herder GJ, van Heesewijk JP, van Strijen MJ (2012) Pulmonary masses: initial results of cone-beam CT guidance with needle planning software for percutaneous lung biopsy. Cardiovasc Intervent Radiol 35:1414-21

18. Brandén E, Wallgren S, Högberg H, Koyi H (2014) Computer tomography-guided core biopsies in a county hospital in Sweden: Complication rate and diagnostic yield. Ann Thorac Med 9:149-53

19. Chakrabarti B, Earis JE, Pandey R et al (2009) Risk assessment of pneumothorax and pulmonary haemorrhage complicating percutaneous co-axial cutting needle lung biopsy. Respir Med 103:449-55

20. Lim C-S, Tan L-E, Wang J-Y et al (2014) Risk factors of pneumothorax after CT-guided coaxial cutting needle lung biopsy through aerated versus nonaerated lung. J Vasc Interv Radiol 25:1209-17

21. Hanninen EL, Vogl TJ, Ricke J, Felix R, Lopez Hanninen E (2001) CT-guided percutaneous core biopsies of pulmonary lesions. Diagnostic accuracy, complications and therapeutic impact. Acta Radiol 42:151-5 
22. Heck SL, Blom P, Berstad A (2006) Accuracy and complications in computed tomography fluoroscopy-guided needle biopsies of lung masses. Eur Radiol 16:1387-92

23. Hiraki T, Mimura H, Gobara $\mathrm{H}$ et al (2010) Incidence of and risk factors for pneumothorax and chest tube placement after CT fluoroscopy-guided percutaneous lung biopsy: retrospective analysis of the procedures conducted over a 9-year period. AJR Am J Roentgenol 194:809-14

24. Khan MF, Straub R, Moghaddam SR et al (2008) Variables affecting the risk of pneumothorax and intrapulmonal hemorrhage in CTguided transthoracic biopsy. Eur Radiol 18:1356-63

25. Kim TJ, Lee JH-H, Lee CT-T et al (2008) Diagnostic accuracy of CT-guided core biopsy of ground-glass opacity pulmonary lesions. AJR Am J Roentgenol 190:234-9

26. Kinoshita F, Kato T, Sugiura K et al (2006) CT-guided transthoracic needle biopsy using a puncture site-down positioning technique. AJR Am J Roentgenol 187:926-32

27. Laurent F, Latrabe V, Vergier B, Montaudon M, Vernejoux JM, Dubrez J (2000) CT-guided transthoracic needle biopsy of pulmonary nodules smaller than $20 \mathrm{~mm}$ : results with an automated 20gauge coaxial cutting needle. Clin Radiol 55:281-7

28. Loubeyre P, Copercini M, Dietrich PY (2005) Percutaneous CTguided multisampling core needle biopsy of thoracic lesions. Am J Roentgenol 185:1294-8

29. Maataoui A, Vogl TJ, Jacobi V, Khan MF (2012) Diagnostic accuracy of CT readings on coin lesions in the lung as compared with transthoracic CT-guided needle biopsy results. Pneumologie 66: 432-6

30. Mendiratta-Lala M, Sheiman R, Brook OR, Gourtsoyianni S, Mahadevan A, Siewert B (2014) CT-guided core biopsy and percutaneous fiducial seed placement in the lung: can these procedures be combined without an increase in complication rate or decrease in technical success? Eur J Radiol

31. Montaudon M, Latrabe V, Pariente A, Corneloup O, Begueret H, Laurent F (2004) Factors influencing accuracy of CT-guided percutaneous biopsies of pulmonary lesions. Eur Radiol 14: 1234-40

32. Patel MV, Ahmed O, Jilani D, Zangan S (2014) Computed tomography-guided percutaneous lung biopsy: impact of lesion proximity to diaphragm on biopsy yield and pneumothorax rate. $\mathrm{J}$ Thorac Imaging 29:344-9

33. Prosch H, Stadler A, Schilling M et al (2012) CT fluoroscopyguided vs. multislice CT biopsy mode-guided lung biopsies: accuracy, complications and radiation dose. Eur J Radiol 81:1029-33

34. Satoh S, Ohdama S, Matsubara O, Okochi Y, Tanaka R, Kimula Y (2005) CT-guided automated cutting needle biopsy by a combined method for accurate specific diagnosis of focal lung lesions. Radiat Med 23:30-6

35. Schoth F, Plumhans C, Kraemer N et al (2010) Evaluation of an interactive breath-hold control system in CT-guided lung biopsy. Röfo 182:507-11

36. Tachibana K, Nakazato Y, Tsuchida S et al (2013) Immediate cytology improves accuracy and decreases complication rate in realtime computed tomography-guided needle lung biopsy. Diagn Cytopathol 41:1063-8

37. Yamagami T, Kato T, Hirota T, Yoshimatsu R, Matsumoto T, Nishimura T (2006) Duration of pneumothorax as a complication of CT-guided lung biopsy. Australas Radiol 50:435-41

38. Yeow K-M, Su I-H, Pan K-T et al (2004) Risk factors of pneumothorax and bleeding: multivariate analysis of $660 \mathrm{CT}$-guided coaxial cutting needle lung biopsies. Chest 126:748-54

39. Yildirim E, Kirbas I, Harman A et al (2009) CT-guided cutting needle lung biopsy using modified coaxial technique: factors effecting risk of complications. Eur J Radiol 70:57-60

40. Covey AM, Gandhi R, Brody LA, Getrajdman G, Thaler HT, Brown KT (2004) Factors associated with pneumothorax and pneumothorax requiring treatment after percutaneous lung biopsy in 443 consecutive patients. J Vasc Interv Radiol 15:479-83

41. D'Alessandro V, Parracino T, Stranieri A et al (2007) Computedtomographic-guided biopsy of thoracic nodules: a revision of 583 lesions. Clin Ter 158:509-13

42. Guimaraes MD, Andrade MQ, Fonte AC, Benevides G, Chojniak R, Gross JL (2010) Predictive complication factors for CT-guided fine needle aspiration biopsy of pulmonary lesions. Clin (Sao Paulo) 65:847-50

43. Kocijancic I, Kocijancic K (2007) CT-guided percutaneous transthoracic needle biopsy of lung lesions - 2-Year experience at the Institute of Radiology in Ljubljana. Radiol Oncol 41:99-106

44. Lang EK, Ghavami R, Schreiner VC, Archibald S, Ramirez J (2000) Autologous blood clot seal to prevent pneumothorax at CT-guided lung biopsy. Radiology 216:93-6

45. Laspas F, Roussakis A, Efthimiadou R, Papaioannou D, Papadopoulos S, Andreou J (2008) Percutaneous CT-guided fineneedle aspiration of pulmonary lesions: results and complications in 409 patients. J Med Imaging Radiat Oncol 52:458-62

46. Lee YS, Jin GY, Han YM, Chung MJ, Park HS (2008) Computed tomography-guided transthoracic needle aspiration biopsy of intrapulmonary lesions: utility of a liquid-based cytopreparatory technique. Acta Cytol 52:665-70

47. Mesurolle B, Mignon F, Meingan P, Domenge C, Vasile M, Sigal R (2003) Head and neck cancer patients with pulmonary nodules: value and role of CT-guided transthoracic needle aspiration biopsies. Head Neck 25:889-94

48. Ng YL, Patsios D, Roberts H et al (2008) CT-guided percutaneous fine-needle aspiration biopsy of pulmonary nodules measuring $10 \mathrm{~mm}$ or less. Clin Radiol 63:272-7

49. Noh TJ, Lee CH, Kang YA et al (2009) Chest computed tomography (CT) immediately after CT-guided transthoracic needle aspiration biopsy as a predictor of overt pneumothorax. Korean J Intern Med 24:343-9

50. Priola AM, Priola SM, Cataldi A et al (2010) Diagnostic accuracy and complication rate of CT-guided fine needle aspiration biopsy of lung lesions: a study based on the experience of the cytopathologist. Acta Radiol 51:527-33

51. Shantaveerappa HN, Mathai MG, Byrd RP Jr, Karnad AB, Mehta JB, Roy TM (2002) Intervention in patients with pneumothorax immediately following CT-guided fine needle aspiration of pulmonary nodules. Med Sci Monit 8:CR401-4

52. Yazar E, Secik F, Yildiz P (2013) Does repeating CT-guided transthoracic fine needle aspiration increase diagnostic yield and complication rate? a single institution experience. Iran J Radiol 10:5660

53. Zhuang YP, Wang HY, Zhang J, Feng Y, Zhang L (2013) Diagnostic accuracy and safety of CT-guided fine needle aspiration biopsy in cavitary pulmonary lesions. Eur J Radiol 82:182-6

54. Wiener RS, Schwartz LM, Woloshin S, Welch HG (2011) Population-based risk for complications after transthoracic needle lung biopsy of a pulmonary nodule: an analysis of discharge records. Ann Intern Med 155:137-44

55. Tomiyama N, Yasuhara Y, Nakajima Y et al (2006) CT-guided needle biopsy of lung lesions: a survey of severe complication based on 9783 biopsies in Japan. Eur J Radiol 59:60-4

56. Gupta S, Wallace MJ, Cardella JF, Kundu S, Miller DL, Rose SC (2010) Quality improvement guidelines for percutaneous needle biopsy. J Vasc Interv Radiol 21:969-75

57. Hiraki T, Fujiwara H, Sakurai J et al (2007) Nonfatal systemic air embolism complicating percutaneous CT-guided transthoracic needle biopsy: four cases from a single institution. Chest 132:684-90

58. Ayar D, Golla B, Lee JY, Nath H (1998) Needle-track metastasis after transthoracic needle biopsy. J Thorac Imaging 13:2-6

59. Freund MC, Petersen J, Goder KC, Bunse T, Wiedermann F, Glodny B (2012) Systemic air embolism during percutaneous core 
needle biopsy of the lung: frequency and risk factors. BMC Pulm Med 12:2

60. Kuban JD, Tam AL, Huang SY, et al (2015) The effect of needle gauge on the risk of pneumothorax and chest tube placement after percutaneous computed tomographic (CT)-guided lung biopsy. Cardiovasc Interv Radiol

61. Priola AM, Novello S, Priola SM et al (2007) Factors effecting risk of pneumothorax (PNX) in CT-guided transthoracic needle biopsy of lung lesions: results of 708 consecutive procedures. J Thorac Oncol 2:S362

62. Choi CM, Um SW, Yoo CG et al (2004) Incidence and risk factors of delayed pneumothorax after transthoracic needle biopsy of the lung. Chest 126:1516-21

63. Saji H, Nakamura H, Tsuchida T et al (2002) The incidence and the risk of pneumothorax and chest tube placement after percutaneous CT-guided lung biopsy: the angle of the needle trajectory is a novel predictor. Chest 121:1521-6

64. Kim GR, Hur J, Lee SM et al (2011) CT fluoroscopy-guided lung biopsy versus conventional CT-guided lung biopsy: a prospective controlled study to assess radiation doses and diagnostic performance. Eur Radiol 21:232-9

65. Prosch H, Schilling M, Stadlert A, Eisenhuber E, Oschatz E, Mostbeck G (2009) CT-fluoroscopy guided versus multislice ct biopsy mode guided lung biopsies: Accuracy, complications and radiation dose. J Thorac Imaging 24:w25

66. Kucuk CU, Yilmaz A, Akkaya E (2004) Computed tomographyguided transthoracic fine-needle aspiration in diagnosis of lung cancer: a comparison of single-pass needle and multiple-pass coaxial needle systems and the value of immediate cytological assessment. Respirology 9:392-6
67. Nour-Eldin N-EA, Alsubhi M, Emam A, et al (2015) Pneumothorax complicating coaxial and non-coaxial CT-guided lung biopsy: comparative analysis of determining risk factors and management of pneumothorax in a retrospective review of 650 patients. Cardiovasc Interv Radiol

68. Bungay HK, Berger J, Traill ZC, Gleeson FV (1999) Pneumothorax post CT-guided lung biopsy: a comparison between detection on chest radiographs and CT. Br J Radiol 72:1160-3

69. Branden E, Wallgren S, Koyi H (2011) CT guided core biopsies in a county hospital in Sweden - Diagnostic yield and complication rate. Chest 140(4)

70. Yamagami T, Iida S, Kato T, Tanaka O, Nishimura T (2003) Combining fine-needle aspiration and core biopsy under CT fluoroscopy guidance: a better way to treat patients with lung nodules? AJR Am J Roentgenol 180:811-5

71. Gong Y, Sneige N, Guo M, Hicks ME, Moran CA (2006) Transthoracic fine-needle aspiration vs concurrent core needle biopsy in diagnosis of intrathoracic lesions: a retrospective comparison of diagnostic accuracy. Am J Clin Pathol 125:438-44

72. Klein JS, Salomon G, Stewart EA (1996) Transthoracic needle biopsy with a coaxially placed 20 -gauge automated cutting needle: results in 122 patients. Radiology 198:715-20

73. Moore W, Sawas A, Lee C, Ferretti J (2011) Needle gauge and cytological yield in CT-guided lung biopsy. ISRN Pulmonol

74. Hasanovic A, Rekhtman N, Sigel CS, Moreira AL (2011) Advances in fine needle aspiration cytology for the diagnosis of pulmonary carcinoma. Patholog Res Int 2011:897292

75. Horeweg N, van Rosmalen J, Heuvelmans MA et al (2014) Lung cancer probability in patients with CT-detected pulmonary nodules: a prespecified analysis of data from the NELSON trial of low-dose CT screening. Lancet Oncol 15:1332-41 